\title{
Plant canopy, tuber yield and growth analysis of potato under moderate and severe drought condition
}

\author{
Abdullah-Al-Mahmud ${ }^{1}$, Md. Altaf Hossain ${ }^{2}$, Md. Abdullah-Al-Mamun ${ }^{3}$, Md. Shamimuzzaman ${ }^{4}$, \\ Ebna Habib Md. Shafiur Rahaman ${ }^{1}$, Md. Shawquat Ali Khan ${ }^{5}$, Md. Mahfuz Bazzaz \\ ${ }^{1}$ International Potato Center (CIP), USAID Horticulture Project, Bangladesh \\ ${ }^{2}$ Tuber Crops Research Centre (TCRC), Bangladesh Agricultural Research Institute (BARI), Joydebpur, Gazipur, Bangladesh \\ ${ }^{3}$ Department of Agriculture Extension (DAE), Rangpur, Bangladesh \\ ${ }^{4}$ Department of Crop Sciences, University of Illinois at Urbana-Champaign, Urbana, Illinois 61801, USA \\ ${ }^{5}$ Agronomy Division, Bangladesh Agricultural Research Institute (BARI), Joydebpur, Gazipur, Bangladesh \\ Email address: \\ Mahmud.tcrc@gmail.com (Abdullah-Al-Mahmud),A.Mahmud@cgiar.org (Abdullah-Al-Mahmud)
}

\section{To cite this article:}

Abdullah-Al-Mahmud, Md. Altaf Hossain, Md. Abdullah-Al-Mamun, Md. Shamimuzzaman, Ebna Habib Md. Shafiur Rahaman, Md. Shawquat Ali Khan, Md. Mahfuz Bazzaz. Plant Canopy, Tuber Yield and Growth Analysis of Potato under Moderate and Severe Drought Condition. Journal of Plant Sciences. Vol. 2, No. 5, 2014, pp. 201-208. doi: 10.11648/j.jps.20140205.18

\begin{abstract}
Four CIP potato clones with 1 check variety Asterix were grown during 2010-11 and 2011-12 at Horticulture Research Farm of Bangabandhu Sheikh Mujibur Rahman Agricultural University, Gazipur, Bangladesh to observe the effect of water stress on canopy structure, yield and growth rate of potato. The study validated that all the genotypes showed reduction in plant height, number of above ground shoots per plant, tuber number per plant and yield by different degrees of drought. Significant yield reduction was found among the genotypes due to drought treatments. Genotype CIP 396244.12 and CIP 393371.58 performed better in severe drought condition in producing higher number of tuber per plant and yield. CIP 396244.12 produced the highest leaf area index in all drought treatments whereas the CIP 391004.18 produced the minimum. In all stage of growth, crop growth rate was affected by different drought treatments where CIP 396244.12 showed the highest crop growth rate followed by CIP 393371.58 and CIP 391004.18 being the lowest. Under severe and moderate drought condition genotype CIP 396244.12 maintained a higher tuber growth rate but under well watered condition CIP 396244.12 and Asterix achieved superior.
\end{abstract}

Keywords: Plant Height, Leaf Area Index, Crop Growth Rate and Tuber Growth Rate

\section{Introduction}

Potato is a cool temperature crop and grown under dry season condition. It also requires good sunshine for normal growth. It is the $4^{\text {th }}$ most important crop in the world [6], and in Bangladesh, potato is ranks second after rice [2]. For its normal growth and development needs regular water supply. Interrupted water supply leads poor plant growth and reduced tuber number and size resulting low yield [10, 16]. Water deficit also decreases number of leaves, plant water potentials [7], leaf area, stem height, ground coverage, tuber growth and yield per plant. It also reduces, canopy radiation interception and to a lesser extent the radiation use efficiency, harvest index, and tuber dry matter content [19].

Drought causes stomatal closure which limits photosynthesis leading to reduced assimilate production and canopy growth which in turns results in lower tuber yield and quality $[8,13,15,16,22]$. According to some authors, to obtain maximum yields soil moisture should not drop below $50 \%$ of crop available water in the soil, although it may vary 25 to $75 \%$. These differences can be explained by climatic, plant and soil characteristics [22].

Irrigation regime is also crucial in determining plant ability to productivity. A well-watered crop is more capable of giving higher yields. Deficit water in irrigation reduces potato yield. The percent of reduction in potato yield may also vary genotype to genotype. It is also related to climatic conditions like day-night air temperatures, relative humidity, soil type, water holding capacity of soil, etc. The influences of temporary water withholding have been widely examined, while little information is obtainable on prolonged moderate water shortage and on its long-term effect. Water shortage affects the canopy structure, stolonization, tuberization, growth, and productivity. During the period of stolon and 
tuber formation the plants are especially sensitive to drought, which reduces the number of tubers [11]. It also affects the total and marketable yield and tuber quality like shape, frequency of abnormalities, dry matter content, size distribution and chemical composition [8].

As water stress in potato is a common phenomenon and its effect has a good impact on growth \& development, it is essential to find out how much a tolerant or a susceptible variety can withstand water stress for prolonged period. Therefore, the present study was under taken i) to determine effects drought effects on the plant canopy and yield ii) to compare the leaf area index, crop growth rate and tuber growth rate under different degrees of drought.

\section{Materials and Methods}

\subsection{Site, Soil and Season of the Experiment}

The experiment was conducted at the Horticultural Research Farm, BSMRAU, Gazipur, Bangladesh during winter season of 2010-11 and 2011-2012. The location of the experimental site was at the center of Madhupur Tract (24.090N latitude and 90.260 longitudes) at $8.5 \mathrm{~m}$ above the sea level. The soil of the experimental field contained $\mathrm{pH} 6.4$. This area is moderately drought prone, and face drought both winter and late winter season [18]. The experimental site is situated in a sub- tropical climate zone and characterized by no rainfall during December to March.

\subsection{Planting Materials and Date of Planting}

Out of five selected potato genotypes, three were relatively tolerant (CIP 393371.58, CIP 396031.119 and CIP 396244.12), one was highly susceptible (CIP 391004.18) and another was high yielding in non-stress condition but susceptible to water stress condition (Asterix) were used in this experiment. Apparently diseases free, uniform $(28-40 \mathrm{~mm})$ sized well sprouted potato were selected as planting material for the experiment. Seed tubers were planted on 25th November, 2010 and 17th November, 2011.

\subsection{Crop Management}

Plant spacing was 60 x $25 \mathrm{~cm}$. Fertilizers were applied @ 160-44-132-15 kg/ha of N, P, K and S, respectively. Full amount of $\mathrm{P}, \mathrm{K}$ and $\mathrm{S}$ and $50 \%$ of $\mathrm{N}$ were applied as basal and the remaining amount of urea was top dressed at 30 days after planting. Intercultural operations such as weeding, earthing up were done manually. Furadan 5G was applied @10 kg/ha as basal during land preparation and Malathion $(0.2 \%)$ sprayed in two installments at 45 and 60 DAP control insects. The crops were also sprayed with Dithane-M $45(0.2 \%)$ and Secure $(0.1 \%)$ ) alternately five times (at $30,40,50,60,70 \mathrm{DAP})$ to prevent the late blight infection of potato [24].

\subsection{Design and Treatments of the Experiment}

The experiment was laid out in the field following strip plot design with three replications. Genotypes were considered as horizontal factor and drought treatment were considered as vertical factor. Three drought treatments were applied (T1= severe drought, $\mathrm{T} 2=$ moderate drought and $\mathrm{T} 3=$ well-irrigated control). In severe drought plots, one irrigation was applied at 30 days after planting for good crop stand, but no irrigation was applied thereafter until harvest. In moderate drought plot, irrigations were applied twice at 30 and 45 days after planting, but no water was applied thereafter till harvest. The control plot was irrigated four times at 30, 45, 60 and 75 days after planting.

\subsection{Climatological Data}

Air temperature and humidity, precipitation, evaporation, soil temperature and ground water table were recorded throughout the crop period (Table 1).

Table 1. Climatological data of 2010-11 and 2011-12 crop season.

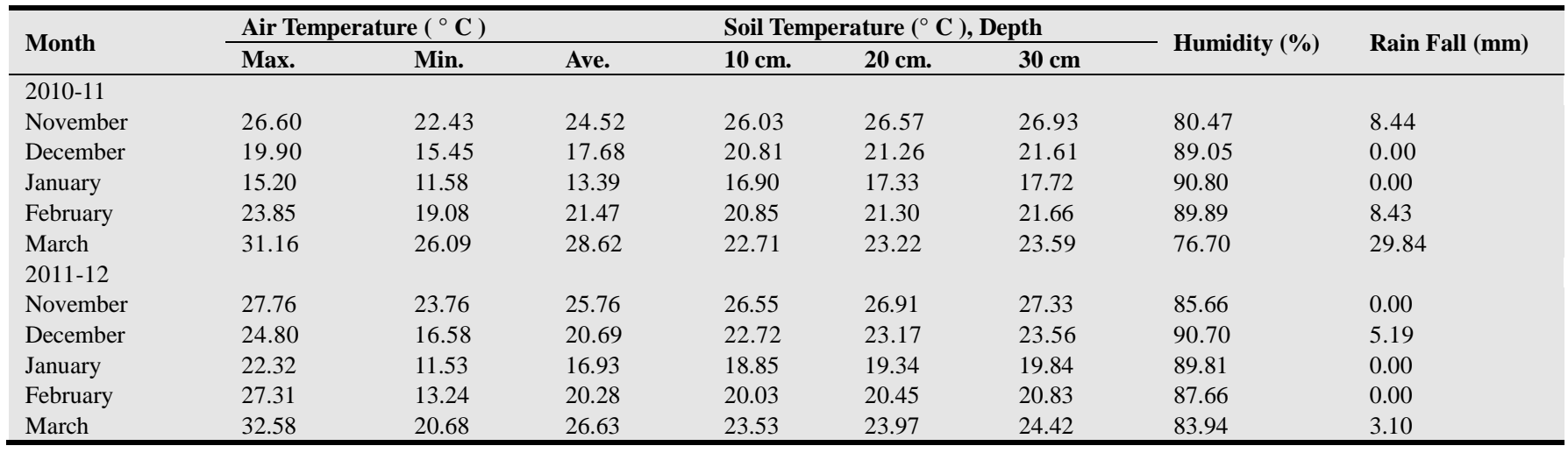

\subsection{Data Collection}

Data were collected on a) plant canopy and b) yield attributes. Under plant canopy parameters data were collected on, i) plant height at 60 days after planting; ii) numbers of above ground shoots per plant at 60 DAP. For yield attributes data were collected on i) tuber number per plant; ii) tuber yield (ton/ha)

\subsection{Sequential Harvest (for Growth Analysis)}

Two plants were harvested from each of plot at each day of 40, 50, 60, 70, 80 and 90. Biomass was divided into leaves, stems, and tubers. Roots were not considered. For each 
biomass group, total fresh weight was determined, and their dry matter was estimated using fraction samples of $150 \mathrm{~g}$ fresh weight (dried in an oven for 48 to 72 hours at $75{ }^{\circ} \mathrm{C}$ until constant weight was achieved).

Leaf Area Index (LAI) was calculated by using the following formula-

$$
\mathrm{LAI}=\frac{\text { Leaf area }}{\text { Land area }}
$$

Crop growth rate (CGR) was calculated by using the following formula-

$$
\mathrm{CGR}=\frac{1 \mathrm{x}(\mathrm{WT} 2-\mathrm{WT} 1)}{\mathrm{LAx}(\mathrm{T} 2-\mathrm{T} 1)} \mathrm{g} \mathrm{m}^{-2} \mathrm{day}^{-1}
$$

Where,

$\mathrm{WT}_{1}=$ Dry weight of tuber at time $\mathrm{T}_{1}$

$\mathrm{WT}_{2}=$ Dry weight of tuber at time $\mathrm{T}_{2}$

$\mathrm{LA}=$ Land area

Tuber growth rate (TGR) was calculated by using the following formula-

$$
\mathrm{TGR}=\frac{1 \times(\mathrm{WT} 2-\mathrm{WT} 1)}{\mathrm{LA} \times(\mathrm{T} 2-\mathrm{T} 1)} \mathrm{g} \mathrm{m}^{-2} \mathrm{day}^{-1}
$$

\subsection{Statistical Analysis}

Combined analyses were done on two years recorded data on different attributes by 'CROSTAT 7.2' statistical package. Appropriate standard errors (S.E.) of the means were calculated.

\section{Results and Discussion}

\begin{tabular}{|c|c|c|c|c|c|c|c|c|}
\hline \multirow{3}{*}{$\begin{array}{l}\text { Genotypes } \\
\text { Treatments }\end{array}$} & \multicolumn{8}{|c|}{ Plant height (cm) } \\
\hline & \multicolumn{4}{|c|}{$2010-11$} & \multicolumn{4}{|l|}{ 2011-12 } \\
\hline & $\begin{array}{l}\text { Severe } \\
\text { drought }\end{array}$ & $\begin{array}{l}\text { Moderate } \\
\text { drought }\end{array}$ & $\begin{array}{l}\text { Well watered } \\
\text { (control) }\end{array}$ & Mean & $\begin{array}{l}\text { Severe } \\
\text { drought }\end{array}$ & $\begin{array}{l}\text { Moderate } \\
\text { drought }\end{array}$ & $\begin{array}{l}\text { Well watered } \\
\text { (control) }\end{array}$ & Mean \\
\hline CIP 391004.18 & 45.96 & 48.63 & 51.00 & 48.53 & 40.12 & 48.80 & 51.47 & 46.80 \\
\hline CIP 393371.58 & 51.30 & 53.20 & 65.00 & 56.50 & 47.10 & 50.36 & 62.50 & 53.32 \\
\hline CIP 96031.119 & 49.26 & 60.06 & 61.33 & 56.88 & 47.82 & 59.05 & 60.24 & 55.70 \\
\hline CIP 396244.12 & 63.63 & 73.36 & 73.50 & 70.16 & 62.13 & 62.81 & 69.78 & 64.91 \\
\hline Asterix & 55.63 & 64.13 & 68.20 & 62.65 & 54.34 & 63.14 & 66.06 & 61.18 \\
\hline Mean & 53.16 & 59.88 & 63.81 & - & 50.30 & 56.83 & 62.01 & - \\
\hline \multicolumn{9}{|c|}{ Statistics (LSD value) } \\
\hline Year $(Y)$ & $0.81 * *$ & & & & & & & \\
\hline Treatments $(\mathrm{T})$ & $0.99 * *$ & & & & & & & \\
\hline $\mathrm{Y} \times \mathrm{T}$ & $1.40^{*}$ & & & & & & & \\
\hline Genotype (G) & $1.28 * *$ & & & & & & & \\
\hline$Y \times G$ & $1.81^{* *}$ & & & & & & & \\
\hline $\mathrm{T} \times \mathrm{G}$ & $2.22 * *$ & & & & & & & \\
\hline$Y \times T \times G$ & $3.14 * *$ & & & & & & & \\
\hline
\end{tabular}

\subsection{Plant Height}

Table 2. Interaction effects of year, treatments and genotypes on plant height during 2010-11 and 2011-12.

$*$ and $* *$ indicates significant at $5 \%$ and $1 \%$ levels of probability

\subsection{No. of above Ground Shoots}

The main effects for years, drought treatments \& genotypic

effects and their interaction effects for above ground shoots per
Main effects of year, treatments \& genotype and their interaction effects on plant height were varied significantly (Table 2). Plant heights in severe drought condition ranged from 45.96 to 63.63 and 40.12 to $62.81 \mathrm{~cm}$ during 2010-11 and 2011-12, respectively. In both the years, CIP 396244.12 exhibited with the tallest plants $(63.63 \mathrm{~cm}$ and $62.13 \mathrm{~cm})$ and CIP 391004.18 produced the shortest plants $(45.96 \mathrm{~cm}$ and $40.12 \mathrm{~cm}$ ). In moderate drought condition, CIP 396244.12 $(73.36 \mathrm{~cm}$ and $62.13 \mathrm{~cm})$ produced the tallest and CIP $391004.18(48.63$ and $48.80 \mathrm{~cm}$ ) produced the smallest plant. In well watered condition, all the genotypes produced comparatively taller plant than severe and moderate drought condition. CIP 396244.12 produced the tallest plant $(73.50 \mathrm{~cm}$ and $69.78 \mathrm{~cm}$ ) and CIP 391004.18 produced the smallest $(51.00 \mathrm{~cm}$ and $51.47 \mathrm{~cm})$. Considering main effects of genotypes, plant height among the genotypes were varied significantly and CIP 396244.12 produced the tallest plant $(70.16 \mathrm{~cm} \mathrm{\&} 64.91 \mathrm{~cm}$ with a mean of $67.53 \mathrm{~cm})$ and CIP 391004.18 produced the smallest $(48.53 \mathrm{~cm}$ and $46.80 \mathrm{~cm}$ with a mean of $47.67 \mathrm{~cm}$ ) plant. Results indicated that plant height of potato was greatly affected by different degrees of drought.

Mean reduction in plant height was $17.75 \%$ and $7.30 \%$ in severe drought and mild drought compare to well watered condition. In this study it is clear that the plant height in CIP 396244.12 was least affected in severe drought and mild drought treatments than other genotypes which indicated that this genotype is quite tolerant to stress environment. Plant height in potato is very sensitive to mild drought conditions were reported by Deblonde and Ladent [4]. Similar findings in potato were also reported by Shaterian et al., [20], Nagaranjan and Bansal, [17] and Schittenhelm et al., [19]. plant were varied significantly (Table 3 ). Average maximum number of above ground shoots per plant was found in CIP 391004.18 (7.08) in 2010 and CIP 96031.119 (6.05) in 2011. But the lowest was found in Genotype CIP 393371.58 produced 
the lowest mean number of 5.45 and 4.50 above ground shoots per plant in 2010-11 and 2011-12, respectively.

The lowest mean above ground shoots per plant was found in severe drought (5.51 and 4.56, respectively) in both the years. In moderate drought condition it was, 6.30 and 5.16, respectively. Comparatively higher numbers of above ground shoots per plant was found in well watered treatments $(6.34$ and 5.65) in 2010-11 and 2011-12.

The highest number of shoots was produced by CIP 391004.18 (7.13) followed by Asterix (5.73) in moderate drought condition during 2010-11. But in 2011-12 Asterix (6.11) produced the maximum. CIP 393371.58 produced the minimum (5.20 and 4.55, respectively) in both the years. CIP 391004.18 produced the mean highest above ground shoots per plant (8.26) during 2010-11 and Asterix (6.50) in 2011-12 in well watered control treatment. The lowest above ground shoots per plant was found in Asterix (5.46) in 2010-11 and CIP 393371.58 (5.00) in 2011-12. Average over the years, CIP 391004.18 produced the highest mean above ground shoot (6.20) followed by Asterix (6.06) and CIP 393371.58 was the lowest (4.96) which was similar to CIP 396244.12 (5.24)) and CIP 396031.119 (5.47.)

Such variation was determined by the tuber size and number of active sprouts per tuber. The numbers of above ground shoots per plant are mainly determined by the size of the tuber [9] and its condition and by soil and soil moisture at planting. It is also influenced by the length and the conditions of the pre-sprouting period.

Similar findings showing the effects of drought on number of shoot per plant were also reported earlier by Wurr [23], Barakat et al., [1] and Deblode and Ladent [4].

Table 3. Interaction effects of drought and genotype on plant height during 2010-11 and 2011-12.

\begin{tabular}{|c|c|c|c|c|c|c|c|c|}
\hline \multirow{3}{*}{$\begin{array}{l}\text { Genotypes } \\
\text { Treatments }\end{array}$} & \multicolumn{8}{|c|}{ Number of above ground shoots per plant } \\
\hline & \multicolumn{4}{|c|}{$2010-11$} & \multicolumn{4}{|l|}{ 2011-12 } \\
\hline & $\begin{array}{l}\text { Severe } \\
\text { drought }\end{array}$ & $\begin{array}{l}\text { Moderate } \\
\text { drought }\end{array}$ & $\begin{array}{l}\text { Well watered } \\
\text { (control) }\end{array}$ & Mean & $\begin{array}{l}\text { Severe } \\
\text { drought }\end{array}$ & $\begin{array}{l}\text { Moderate } \\
\text { drought }\end{array}$ & $\begin{array}{l}\text { Well watered } \\
\text { (control) }\end{array}$ & Mean \\
\hline CIP 391004.18 & 5.86 & 7.13 & 8.26 & 7.08 & 4.49 & 5.50 & 5.94 & 5.31 \\
\hline CIP 393371.58 & 5.16 & 5.20 & 6.00 & 5.45 & 3.95 & 4.55 & 5.00 & 4.50 \\
\hline CIP 96031.119 & 6.03 & 6.73 & 5.80 & 6.19 & 3.86 & 4.77 & 5.61 & 4.75 \\
\hline CIP 396244.12 & 4.60 & 5.60 & 6.20 & 5.47 & 4.94 & 4.88 & 5.22 & 5.01 \\
\hline Asterix & 5.93 & 6.83 & 5.46 & 6.07 & 5.54 & 6.11 & 6.50 & 6.05 \\
\hline Mean & 5.51 & 6.30 & 6.34 & & 4.56 & 5.16 & 5.65 & \\
\hline \multicolumn{9}{|c|}{ Statistics (LSD value) } \\
\hline Year $(Y)$ & \multicolumn{8}{|c|}{$0.34 * *$} \\
\hline Treatments $(\mathrm{T})$ & \multicolumn{8}{|c|}{$0.42 * *$} \\
\hline $\mathrm{Y} \times \mathrm{T}$ & \multicolumn{8}{|c|}{$0.59 \mathrm{~ns}$} \\
\hline Genotype (G) & \multicolumn{8}{|c|}{$0.54 * *$} \\
\hline$Y \times G$ & \multicolumn{8}{|c|}{$0.77 * *$} \\
\hline $\mathrm{T} \times \mathrm{G}$ & \multicolumn{8}{|c|}{$0.94 \mathrm{~ns}$} \\
\hline$Y \times T \times G$ & \multicolumn{8}{|c|}{$1.91 \mathrm{~ns}$} \\
\hline
\end{tabular}

$*$ and $* *$ indicates significant at $5 \%$ and $1 \%$ levels of probability, ns= not significant

\subsection{Tuber Number}

Main effects of drought treatment, genotypic effects and their interaction effects for tuber number per plant were varied significantly. Tuber number per plant ranged from 5.76 to 10.80 in $2010-11 \& 7.23$ to 10.42 in $2011-12$, respectively (Table 4). In severe drought condition, the maximum tuber per plant was found in CIP 396244.12 (9.00) which was similar to CIP 396031.119 (8.00) in 2010-11. But in 2011-12, CIP 393371.58 (8.16) produced the highest tuber number per plant CIP 391004.18 produced the minimum tuber per plant (5.76 and 7.23) in both the years. Tuber in mild drought treatment, the highest was in CIP 396031.119 (9.80) in 2010-11 and Asterix (9.68) in 2011-12. CIP 393371.58 produced the minimum tuber number per plant $(7.73$ and 8.35$)$ in both the years. In well watered control, CIP 391004.18 produced the maximum (10.80) in 2010-11 and Asterix (10.42) in 2011-12. On the other hand CIP 393371.58 (7.80) produced the minimum tuber number per plant in 2010-11 and CIP 396244.12 (8.48) in 2011-12. Mean highest tuber per plant was found in well watered condition (9.18 and 9.72) than moderate drought (8.77 and 9.04) and severe drought treated plots (7.38 and 7.70). The mean highest was in CIP 396031.119 (9.19) which was similar to Asterix (8.77), and CIP 391004.18 (8.73) and CIP 393371.58 (8.19) produced the lowest tuber number per plant. Results indicated that the number of tubers per plant adversely affected by deficit water.

Mean reduction in tuber number per plant were $21.37 \%$ and $8.83 \%$ in severe drought and moderate drought condition, respectively. A gradual decrease in tuber number was observed with a gradual increase of water stress. Present results agree with previous studies of Haverkort et al., [11], Levy [14], and Hassanpanh [9]. Tuber number is very sensitive to mild drought was also reported by Deblonde and Ladent [4]. 
Table 4. Interaction effects of drought and genotype on tuber number per plant during 2010-11 and 2011-12.

\begin{tabular}{|c|c|c|c|c|c|c|c|c|}
\hline \multirow{3}{*}{$\begin{array}{l}\text { Genotypes } \\
\text { Treatments }\end{array}$} & \multicolumn{8}{|c|}{ Tuber number per plant } \\
\hline & \multicolumn{4}{|c|}{$2010-11$} & \multicolumn{4}{|l|}{ 2011-12 } \\
\hline & $\begin{array}{l}\text { Severe } \\
\text { drought }\end{array}$ & $\begin{array}{l}\text { Moderate } \\
\text { drought }\end{array}$ & $\begin{array}{l}\text { Well watered } \\
\text { (control) }\end{array}$ & Mean & $\begin{array}{l}\text { Severe } \\
\text { drought }\end{array}$ & $\begin{array}{l}\text { Moderate } \\
\text { drought }\end{array}$ & $\begin{array}{l}\text { Well watered } \\
\text { (control) }\end{array}$ & Mean \\
\hline CIP 391004.18 & 5.76 & 9.73 & 10.80 & 8.76 & 7.23 & 9.28 & 9.54 & 8.68 \\
\hline CIP 393371.58 & 7.13 & 7.73 & 7.80 & 7.55 & 8.16 & 8.35 & 10.00 & 8.84 \\
\hline CIP 96031.119 & 8.00 & 9.80 & 9.96 & 9.25 & 8.05 & 9.17 & 10.18 & 9.13 \\
\hline CIP 396244.12 & 8.10 & 8.16 & 9.00 & 8.42 & 7.26 & 8.48 & 8.72 & 8.15 \\
\hline Mean & 7.20 & 8.78 & 9.35 & & 7.70 & 8.99 & 9.77 & \\
\hline \multicolumn{9}{|c|}{ Statistics (LSD value) } \\
\hline Year $(Y)$ & \multicolumn{2}{|c|}{$0.49 \mathrm{~ns}$} & & & & & & \\
\hline Treatments (T) & \multicolumn{2}{|c|}{$0.60 * *$} & & & & & & \\
\hline $\mathrm{Y} \times \mathrm{T}$ & \multicolumn{2}{|c|}{$0.86 \mathrm{~ns}$} & & & & & & \\
\hline Genotype (G) & \multicolumn{2}{|c|}{$0.78 * *$} & & & & & & \\
\hline$Y \times G$ & \multicolumn{2}{|c|}{$1.10 \mathrm{~ns}$} & & & & & & \\
\hline$Y \times T \times G$ & \multicolumn{2}{|c|}{$1.34 \mathrm{~ns}$} & & & & & & \\
\hline
\end{tabular}

$*$ and $* *$ indicates 0.05 and 0.01 levels of probability, ns= not significant

\subsection{Tuber Yield}

The main effects of year, treatment, genotype and their interaction for tuber yield per ha showed significant variation and ranged from 11.27 to 32.57 ton/ha in $2010-11$ and 10.36 to 28.61 ton/ha in 2011-12 (Table 5). In severe drought condition, the highest yield was observed in CIP 396244.12 (14.64 ton/ha and 13.56 ton/ha with a mean of 14.10 ton/ha) which was similar to CIP 393371.58 (14.38 ton/ha and 10.69 ton/ha with a mean of $12.53 \mathrm{t} / \mathrm{ha}$ ) and the CIP 391004.18 (11.27 ton/ha and 10.36 ton/ha with a mean of 10.82 ton) was the lowest. In mild drought condition, it ranged from 21.12 to 24.38 ton/ha in 2010-11 and 17.44 to 22.65 ton/ha in 2011-12. Average of the year, CIP 396244.12 produced the highest (23.38 t/ha) which was similar to Asterix (23.02 t/ha) and CIP 393371.58 (21.28 t/ha). CIP 391004.18 produced the lowest (19.28 t/ha). Higher yield increase was observed in all genotypes in well watered control condition and ranging from 25.79 to 32.57 ton/ha in $2010-11$ and 22.08 to 28.61 ton/ha in 2011-12. Average over the year, Asterix produced the highest yield (30.59 ton)/ha which was similar to CIP 396244.12 (28.82 t/ha). CIP 393371.58 was the mean lowest yielder (24.14 t/ha) which was similar to CIP 391004.18 (24.45 t/ha). Among the genotypes, the mean yield of the two years was the highest in CIP 396244.12 (22.15 ton) which was similar to Asterix (21.93 ton) while CIP 391004.18 produced the lowest (18.18 ton).

In severe drought and mild drought conditions, mean yield reduction were $54.72 \% \& 20.14 \%$ in $2010-11$ and $54.84 \%$ \& $21.64 \%$ in 2011-12, respectively. Under stress conditions CIP 396244.12 and CIP 393371.58 performed better, but in well watered condition Asterix gave the highest yield followed by CIP 396244.12 and CIP 393371.58. Therefore, CIP 393371.58 and CIP 396244.12 have good yield potentials under both conditions. The findings were in agreement with Struik and Voorst [21], Deblonde and Ladent [4], Heuer and Nadler [12], Hassanpanh [9]. Deblonde et al., [3] reported that severe drought treatment adversely affected tuber yield.

Table 5. Interaction effects of drought and genotype on yield (ton/ha) per plant during 2010-11 and 2011-12.

\begin{tabular}{|c|c|c|c|c|c|c|c|c|}
\hline \multirow{3}{*}{$\begin{array}{l}\text { Genotypes } \\
\text { Treatments }\end{array}$} & \multicolumn{8}{|c|}{ Tuber yield (ton/ha) } \\
\hline & \multicolumn{4}{|c|}{$2010-11$} & \multicolumn{4}{|l|}{ 2011-12 } \\
\hline & $\begin{array}{l}\text { Severe } \\
\text { drought }\end{array}$ & $\begin{array}{l}\text { Moderate } \\
\text { drought }\end{array}$ & $\begin{array}{l}\text { Well watered } \\
\text { (control) }\end{array}$ & Mean & $\begin{array}{l}\text { Severe } \\
\text { drought }\end{array}$ & $\begin{array}{l}\text { Moderate } \\
\text { drought }\end{array}$ & $\begin{array}{l}\text { Well watered } \\
\text { (control) }\end{array}$ & Mean \\
\hline CIP 391004.18 & 11.27 & 21.12 & 25.79 & 19.39 & 10.36 & 17.44 & 23.11 & 16.97 \\
\hline CIP 393371.58 & 14.38 & 24.23 & 27.94 & 22.18 & 10.69 & 18.32 & 28.15 & 19.05 \\
\hline CIP 96031.119 & 11.68 & 21.22 & 26.20 & 19.70 & 11.48 & 19.28 & 22.08 & 17.61 \\
\hline CIP 396244.12 & 14.64 & 24.11 & 32.22 & 23.66 & 13.56 & 22.65 & 25.68 & 20.63 \\
\hline Asterix & 13.42 & 24.38 & 32.57 & 23.46 & 10.93 & 21.67 & 28.61 & 20.40 \\
\hline Mean & 13.08 & 23.01 & 28.94 & & 11.40 & 19.87 & 25.53 & \\
\hline \multicolumn{9}{|c|}{ Statistics (LSD value) } \\
\hline Year $(\mathrm{Y})$ & \multicolumn{2}{|c|}{$0.64 * *$} & & & & & & \\
\hline Treatments (T) & \multicolumn{2}{|c|}{$0.79 * *$} & & & & & & \\
\hline $\mathrm{Y} \times \mathrm{T}$ & \multicolumn{2}{|c|}{$1.12 \mathrm{~ns}$} & & & & & & \\
\hline Genotype (G) & \multicolumn{2}{|c|}{$1.02 * *$} & & & & & & \\
\hline$Y \times G$ & \multicolumn{2}{|c|}{$1.44 \mathrm{~ns}$} & & & & & & \\
\hline $\mathrm{T} \times \mathrm{G}$ & \multicolumn{2}{|c|}{$1.77 * *$} & & & & & & \\
\hline$Y \times T \times G$ & \multicolumn{2}{|c|}{$2.50 * *$} & & & & & & \\
\hline
\end{tabular}

$*$ and $* *$ indicates 0.05 and 0.01 levels of probability, $\mathrm{ns}=$ not significant 


\subsection{Leaf Area Index}

Leaf area index (LAI) of five potato genotypes were measured at $60 \mathrm{DAP}$ at field condition (Figure 1). LAI varied significantly among the genotypes with different treatment combination. Mean lowest LAI (2.01) was observed in severe drought and mild drought treatments (2.56). In severe drought condition, LAI varied from 1.37 to 2.53 , where the lowest was found in CIP 391004.18 and the highest was in CIP 396244.12. In mild drought condition, LAI varied from 1.80 to 3.01, where the lowest was found in CIP 391004.18 and the highest was in CIP 396244.12 followed by Asterix (3.00). In well watered condition, LAI varied from 2.30 to 3.86 , where the lowest was found in CIP 391004.18 and the highest was in Asterix followed by CIP 396244.12 (3.46). In this study, larger LAI was observed in CIP 396244.12 in both the conditions. Higher LAI indicated that plants were able to produce more photosynthates under drought situation that ultimately resulted in good tuber yield. Therefore, larger LAI is an indicator of drought tolerance.

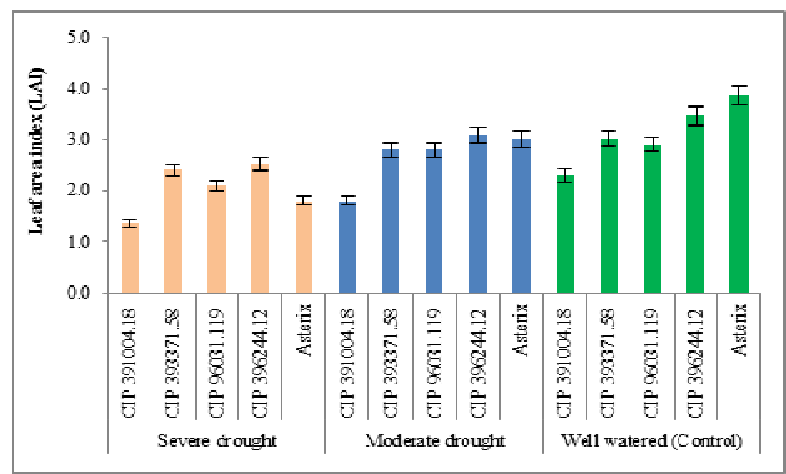

Figure 1. Leaf area index of five potato genotypes at 60 DAP (Mean of 2010-11and 2011-12).

\subsection{Crop Growth Rate}

The crop growth rates (CGR) of the five potato genotypes were studied at different growth stages (figure 2.1, $2.2 \& 2.3$ ). In all the genotypes the CGR increased up to 50-60 days after planting under both control and moderate drought treatment, but decreased under severe drought treatment. Under severe drought condition, the CGR decreased sharply in CIP 391004.18, CIP 393371.58,

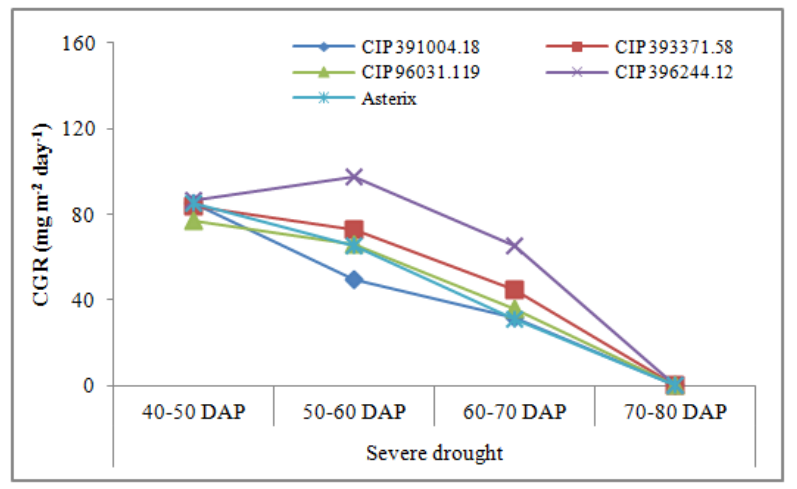

Figure 2.1

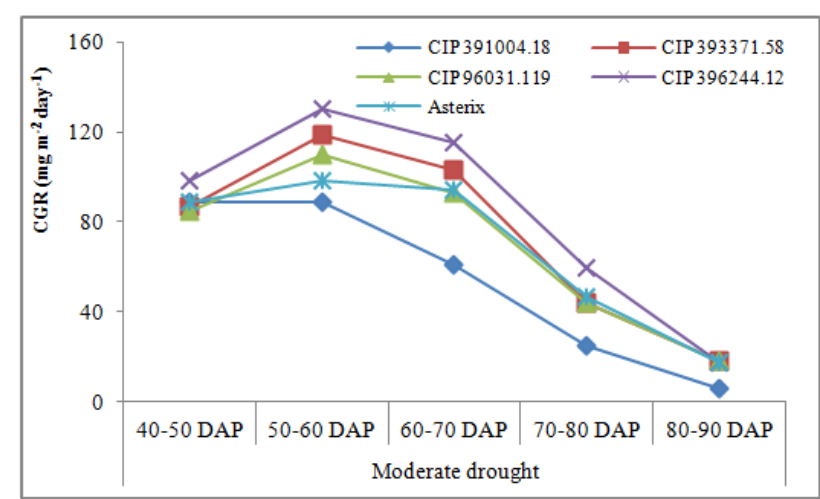

Figure 2.2

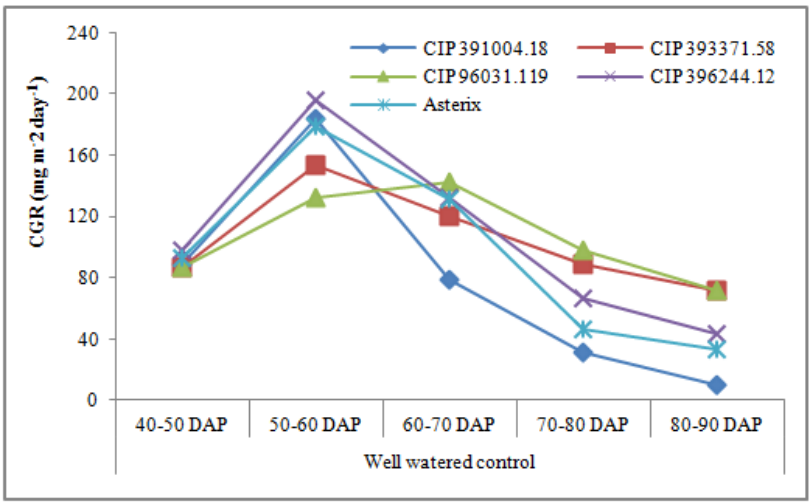

Figure 2.3

Figure 2.(1-3). Crop growth rates (CGR) of five potato genotypes under different drought treatment (Mean of 2010-11and 2011-12)

CIP 396031.119 and Asterix from 40-50 days after planting, but CIP 396244.12 showed increase up to 50-60 days after planting and then declined. Marked variation was observed among the genotypes at 50-60 and 60-70 days after planting. At both the stages, CIP 396244.12 showed the highest CGR followed by CIP 393371.58 while CIP 391004.18 showed the lowest. The cessation in CGR in all the genotypes was found at 70-80 days after planting stage. All the genotypes showed higher CGRs under moderate drought condition than severe drought. Increasing trend was found up to 50-60 days after planting stage and then declined with time. Marked variation was observed among the genotypes at 50-60 to 70-80 days after planting stages. In all stage of growth, CIP 396244.12 showed the highest CGR followed by CIP 393371.58 while CIP 391004.18 showed the lowest. Maintaining a good CGR under moderate and severe drought conditions is an indication of drought tolerance. The higher CGRs were found in control than severe and moderate drought treatments in all the genotypes. Increasing trend was found up to 50-60 days after planting stage and then declined with time. Marked variation was observed among the genotypes at 50-60 to 80-90 days after planting stages. At 50-60 days after planting stage the highest CGR was found in CIP 396244.12 followed by Asterix, CIP 391004.18 and CIP 393371.58, while CIP 396031.119 was the lowest. At 60-70 DAP, CIP 393371.58 showed the highest CGR with increasing trend but the rest others showed 
a decreasing trend, where CIP 391004.18 was the lowest and continued up to harvest. Decreasing CGR at early stage indicates that the crop has early maturing tendency. From this study it is clear that CIP 391004.18 is an early maturing genotype. Similarly, CIP 396244.12 have early maturing tendency but CIP 396031.119 has late maturing tendency. Rest two genotypes Asterix and CIP 393371.58 took 90 days for maturity.

\subsection{Tuber Growth Rate}

The tuber growth rate (TGR) of the five potato genotypes were studied from 40 to 90 days after planting. TGRs of all genotypes increased up to 50-60 days after planting under both control and moderate drought treatment (figure 3.2 \&3.3). Under severe drought condition, marked variation in TGR was observed at 50-60 and 60-70 days after planting stages, but afterwards, it decreased sharply and stopped (figure 3.1). CIP 396244.12 showed the highest TGR up to 60-70 days after planting which indicated that the genotype have the capacity to produce good tuber yield under severe drought condition. CIP 391004.18 showed rapid decrease in TGR which indicated its quick bulking tendency under severe drought condition.

Under moderate drought condition, marked variation was observed among the genotypes at 50-60 to 70-80 days after planting stages (figure 3.2). Genotype CIP 396244.12, CIP 393371.58 and Asterix maintained good TGRs up to 60-70 days after planting. At 70-80 days after planting to maturity, all the genotypes showed similar trends in TGR. Under control condition, all the genotypes showed higher TGR than severe and moderate drought treatments. The highest pick was found at 60-70 days after planting in CIP 393371.58, CIP 396031.119, CIP 396244.12 and Asterix. CIP 391004.18 showed the highest pick at 50-60 days after planting and then declined gradually. Marked variation was observed among the genotypes at 50-60 and 60-70 days after planting stages. At 50-60 days after planting, the highest TGR was found in CIP 396244.12 followed by Asterix, CIP 396031.119, CIP 393371.58 and CIP 391004.18, while Asterix was the lowest. At 60-70 days after planting the different scenario in TGR was observed where Asterix was the highest, followed by CIP 396244.12, CIP 396031.119 and CIP 393371.58. At this stage CIP 391004.18 showed the lowest TGR which indicates that the genotype was early maturing type. On the other hand CIP 396244.12, CIP 393371.58 and Asterix showed almost similar TGR at maturity, so they mature at same time. But CIP 396031.119 showed highest TGR at harvest which indicated that the genotype takes slight more time to maturity.

\section{Conclusion}

Plant canopy structure and yield were affected by different degrees of drought. Genotypic variation also found among the genotypes in producing canopy and yield. The tolerant genotypes showed comparatively less reduction in plant height, above ground shoots per plant, tuber number per plant and yield. The lowest reduction in tuber yield was found in
CIP 396244.12 followed by CIP 393371.58. The mean production was higher in 2010 and it was environmental. The lowest LAI was observed in severe drought condition. CIP 396244.12 and CIP 393371.58 showed higher LAI indicated that they were comparatively more productive under severe drought condition than others. These two genotypes CIP 396244.12 and CIP 393371.58 maintained higher crop growth rate and tuber growth rate during the crop growing period under severe and moderate drought condition that resulted in good yield under drought condition.

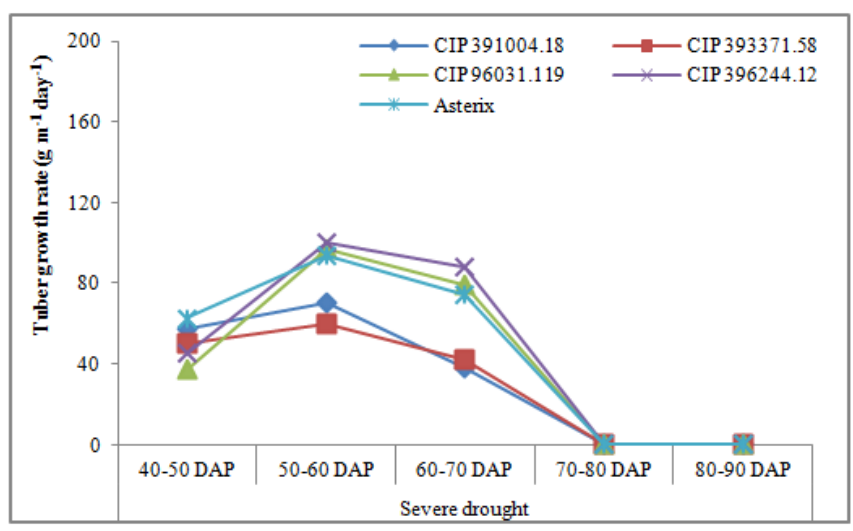

Figure 3.1

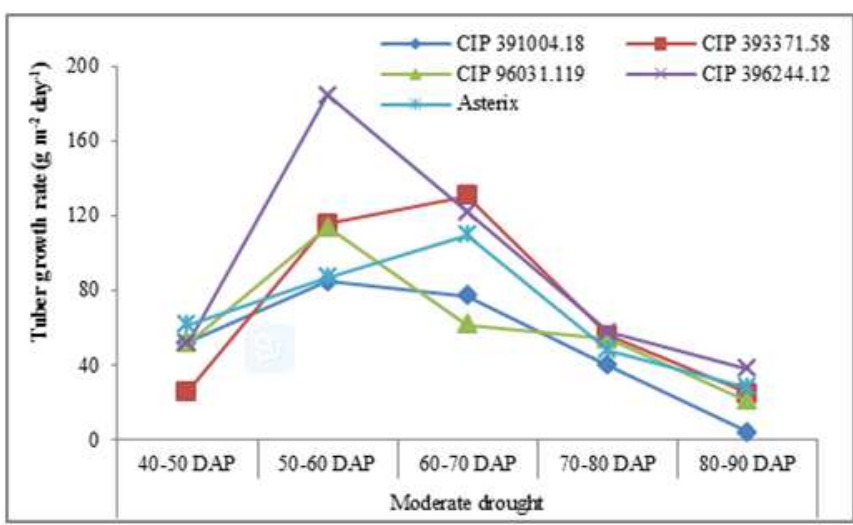

Figure 3.2

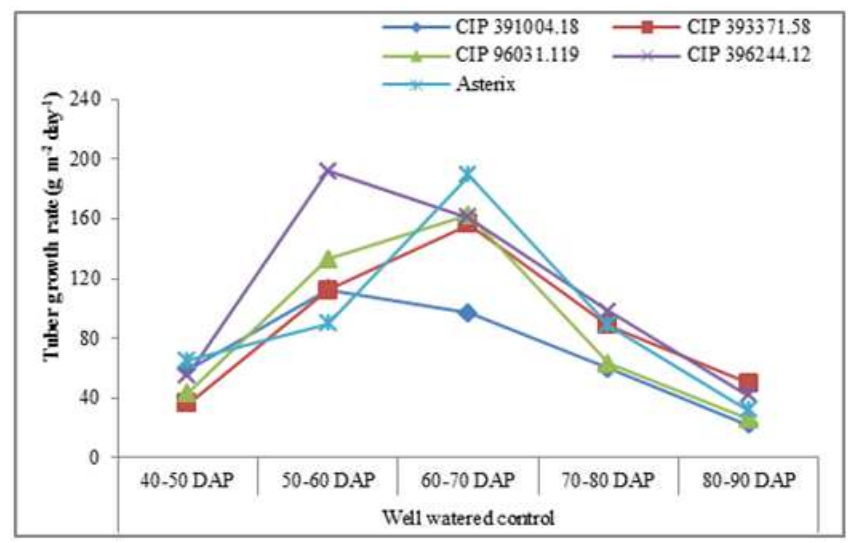

Figure 3.3

Figure 3.(1-3). Tuber growth rates of five potato genotypes under different drought treatment (Mean of 2010-11and 2011-12) 


\section{Acknowledgements}

The authors are thankful to the Director General of Bangladesh Agricultural Research Institute (BARI) for the financial support through a fellowship and also the Department of Horticulture, Bangabandhu Sheikh Mujibur Rahman Agricultural University for providing the research facilities.

\section{References}

[1] Barakat, M.A.S.S., M. El-Araby, and F.I. Adgham. 1994. Varietal response of potato to graded dose of nitrogen and potassium. Alex. Agric. Res. 39 (34): 399 - 414.

[2] BBS. 2010. Year book of Agricultural Statistics of Bangladesh, Bangladesh Bureau of Statistics (BBS), Ministry of planning, Government of the People's Republic of Bangladesh.

[3] Deblonde, P.K.M., A.J. Haverkort, and J.F. Ladent.1999. Response of early and late potato cultivars to moderate drought conditions: agronomic parameters and carbon isotope discrimination. Europ. J. Agronomy. 11: 91-105.

[4] Deblonde, P.M.K. and J.F. Ladent. 2001. Effects of moderate drought conditions on green leaf number, stem height, leaf length and tuber yield of potato cultivars. European Journal of Agronomy. 14: 31-41.

[5] Dey, T.K., Z.H. Prodhan, and M.S. Hossain. 2007. Potato Late Blight and its Integrated Management. (Booklet in Bengali). Breeders Seed Production Centre. Bangladesh Agricultural Research Institute, Debiganj, Panchagarh, Bangladesh.

[6] Fernie, A.R., and L. Willmitzer. 2001. Molecular and biochemical triggers of tuber development. Plant Physiol. 127: 1459-1465.

[7] French, J. 1997. Primary response of root and leaf elongation to water deficits in the atmosphere and soil solution. J. Exp. Bot. 48 (310): 985-999.

[8] Gregory, P.J. and L.P. Simmonds. 1992. Water relations and growth of potatoes. In: P.M.Harris (Ed.) The potato crop- The scientific basis for improvement. 2nd ed. Chapman and Hall, London. pp. 214-246.

[9] Hassanpanah, D. 2010. Evaluation of Potato Advanced Cultivars against Water Deficit Stress Under in vitro and in vivo Condition. Biotechnology. 9(2): 164-169.

[10] Hassanpanah, D., E. Gurbanov, A. Gadimov, and R. Shahriari. 2008. Determination of yield stability in advanced potato cultivars as affected by water deficit and potassium humate in Ardabil region, Iran. Pak. J. Biol. Sci. 15: 1354-1359.
[11] Havaerkort, A.J., M. van de Waart, and K.B.A. Bodlaender.1990. The effect of early drought stress on numbers of tubers and stolons of potato in controlled and field conditions. Potato Research. 33: 89-96.

[12] Heuer, B. and A. Nadler. 1998. Physiological response of potato plants to soil salinity and water deficit. Plant Science. 137: 43-51.

[13] Jefferies, R. A. 1989. Water stress and leaf growth in field-grown crops of potato (Solanum tuberosum L.). Journal of Experimental Botany. 40: 1375-1381.

[14] Levy, D. 1992. Osmotic potential of potatoes subjected to a single cycle of water deficit. Potato research. 35: 17-24.

[15] Mackerron, D.K.L. and R.A. Jefferies. 1988. The distribution of tuber sizes in droughted and irrigated crops of potato. I. Observation on the effect of water stress on graded yields from differing cultivars. Potato Research. 31: 269-278.

[16] Miller, D.E. and M.W. Martin. 1985. Effect of declining or interrupted irrigation on yield and quality of three potato cultivars grown on a sandy soil. Am. Potato J. 64: 109-117.

[17] Nagaranjan, S. and K.C. Bansal. 1991. Growth and distribution of dry matter in a drought tolerant and a susceptible potato cultivar under normal and water deficit condition. J. Agronomy \& Crop Science. 167: 112-118.

[18] Ramamasy, S. and S. Baas. 2007. Climate variability and change: Adaptation to drought in Bangladesh. A resource book and training guide. Asian Disaster Preparedness Center, Food and Agriculture Organization of the United Nations, Rome.

[19] Schittenhelm, S., H. Sourell and F.J. LÖpmeier. 2006. Drought resistance of potato cultivars with contrasting canopy architecture. Europ. J. Agronomy. 24: 193-202.

[20] Shaterian, J., D. R. Waterer, H. de Jong and K.K. Tanino. 2008. Methodologies and traits for evaluating the salt tolerance in diploid potato clones. Am. J. Pot. Res. 85: 93-100.

[21] Struik, P. C. and G. van Voorst. 1986. Effects of drought on the initiation, yield and size distribution of tubers of Solanun tuberosum L. cv. Bintje. Potato Research. 29: 487-500.

[22] Van Loon, C.D. 1981. The effect of water stress on potato growth, development and yield. Amer. Potato J. 58: 51-69.

[23] Wurr, D.C.E. 1974. Some effects of seed size and spacing on the yield and grading of two main potato varieties. I. Final yield and its relation to plant population. Journal of Agricultural Science, Cambridge. 82: 37-45.

[24] Wurr, D.C.E., C.C. Hole, Jane R. Fellows, Jane Milling, J.R. Lynn and P.J. Obrien. 1997. The effect of some environmental factors on potato tuber Numbers. Potato Research. 40: 297-306. 